\title{
Aging during COVID-19 in Germany: a longitudinal analysis of psychosocial adaptation
}

\author{
Anna Schlomann ${ }^{1,2} \cdot$ Mareike Bünning $^{3,4} \cdot$ Lena Hipp $^{3,5} \cdot$ Hans-Werner Wahl ${ }^{1,6}$
}

Accepted: 17 September 2021 / Published online: 1 October 2021

(c) The Author(s) 2021

\begin{abstract}
Existing theories of aging suggest that there may be similarities and differences in how COVID-19 impacts older people's psychosocial adaptation compared to younger age groups, particularly middle-aged individuals. To assess the degree to which these impacts vary, we analyzed data from 3098 participants between the ages of 40 and 79 from an online survey in Germany. Data were collected at three measurement occasions between the start of the nationwide lockdown in mid-March 2020 and the end of the lockdown in early August 2020. The survey focused on everyday experiences during the COVID19 crisis and collected various satisfaction ratings (e.g., general life satisfaction, satisfaction with family life, satisfaction with social contacts). At baseline, participants also provided retrospective ratings of satisfaction for the period before the COVID-19 crisis. In our analyses, we compared satisfaction ratings of middle-aged (40-64 years) and older individuals (65-79 years) and found that both middle-aged and older participants experienced the greatest decreases in satisfaction with social contacts, with more pronounced decreases seen in middle-aged participants. A similar pattern was observed for general life satisfaction, but the overall decreases were less pronounced in both groups compared to the decreases in satisfaction with social contacts. We also observed a partial recovery effect in all measures at the last measurement occasion, and this effect was more pronounced in older adults. Findings were also confirmed using age as a continuous variable and checking for linear and nonlinear effects of outcomes across the age range. Although ageism arose during the pandemic in the sense that older adults were labeled as a "risk group," particularly at the start of the outbreak, we found consistently with other studies that middle-aged adults' satisfaction decreased to a greater extent than that of older adults.
\end{abstract}

Keywords Coronavirus pandemic $\cdot$ Older adults $\cdot$ Satisfaction with life $\cdot$ Satisfaction with social relations $\cdot$ Age stereotypes $\cdot$ Longitudinal survey study

Responsible Editor: Matthias Kliegel.

Anna Schlomann and Mareike Bünning contributed equally to this paper.

Anna Schlomann

schlomann@ nar.uni-heidelberg.de

1 Network Aging Research, Heidelberg University, Bergheimer Straße 20, 69115 Heidelberg, Germany

2 Institute for Educational Sciences, Heidelberg University of Education, Heidelberg, Germany

3 WZB Berlin Social Science Center, Berlin, Germany

4 German Center of Gerontology (DZA), Berlin, Germany

5 University of Potsdam, Potsdam, Germany

6 Institute of Psychology, Heidelberg University, Heidelberg, Germany

\section{Introduction}

As has been officially documented and reported across a large number of countries, older adults were the most severely affected of all age groups by the COVID-19 pandemic in terms of their health and lives (WHO 2020). However, not much is known about how the crisis has affected older adults' life satisfaction and psychological adaptation compared to other age groups-middle-aged adults, in particular. As older adults were negatively stereotyped as a "risk group" during the crisis due to their chronological age (Ayalon et al. 2021; Ehni and Wahl 2020; JiminezSotomayor et al. 2020), it may well be that older individuals were affected differently by the COVID-19 pandemic than younger age groups. 


\section{Psychosocial challenges for older adults during the COVID-19 crisis}

The SARS-CoV2 virus created an unexpectedly stressful situation for individuals around the globe, including both community-dwelling older adults as well as older adults living in long-term care settings (Sands et al. 2020). This article looks at community-dwelling older adults. In Germany, where we conducted our study, older adults were affected by the crisis in at least four ways. First, data on mortality caused by COVID-19 infections were regularly published and discussed by the press and media; such reports clearly indicated that survival after hospitalization, particularly after ventilator treatment, was significantly lower in older adults (Wolf-Ostermann and Rothgang 2020).

Second, the ongoing discussion on the availability of intensive care beds (ICBs) and public communications on the possible need for triage in case of a shortage of ICBs raised fears among older adults that, if infected, they would not receive optimal medical treatment and would be accorded a lower priority, due primarily to their chronological age (Ehni and Wahl 2020). Television reports on the situation in other European countries-in particular, Italy, France, and Spain-suggested that age-based triage may have been utilized due to ICB shortages. Images in the media of military trucks in Italy being used to transport scores of coffins may have exacerbated such fears among older adults in Germany (see also Cesari and Proietti 2020).

Third, the lockdown, which began in Germany in midMarch 2020, led to complete social isolation among older adults in nursing homes, but the same was also largely true for older people living in the community. Many valuable activities for older adults, such as visiting or being visited by children and grandchildren, shopping, eating out, going to cultural events, taking walks with peers, volunteering, or participating in educational programs, were out of the question. Constraints on social interactions and activities were among the greatest challenges facing older adults in the initial phase of the pandemic (Heid et al. 2021). The resulting separation from family and close friends put older adults at risk of loneliness, which can eventually lead to physical and mental health decline (Tyrrell and Williams 2020). At this point in time, it was also unclear how long the situation would last.

Fourth, older adults faced ageism and negative age stereotyping in that they were seen as the major "risk group" who had to be protected by the lockdown and who had forced younger age groups to stay home, minimize activity, and stop going to school-a development that had dramatic impacts on parents' lives and childcare duties (Ayalon et al. 2021; Ehni and Wahl 2020).
The current paper addresses how middle-aged (40-64 years) and older adults (65-79 years) have psychologically adapted to the COVID-19 crisis in Germany covering a timespan with three measurement occasions from the point in time when the outbreak caused a country-wide lockdown to the end of the lockdown about five months later.

\section{Conceptual approach}

To conceptually capture the pandemic's psychosocial consequences, we draw on socio-emotional selectivity theory and stress and resilience theory. First, socio-emotional selectivity theory (Carstensen 2006; English and Carstensen 2016; see also Martin 2020) argues that if time is perceived as limited, which is typically the case in old age and may have been reinforced by the COVID-19 crisis, people value emotionally meaningful goals and relationships more than other goals in life. This activates mood-enhancing goals and reduces the willingness to accept temporary negative experiences for the sake of long-term benefits. Findings related to socio-emotional selectivity theory have shed light on a phenomenon referred to as the positivity effect of aging (Scheibe and Carstensen 2010). The positivity effect relates to a shift that occurs with advancing age toward paying attention to or remembering positive as opposed to negative information.

A second theoretical lens through which to analyze the crisis's impact on individual well-being is stress theory (Lazarus 1993). The COVID-19 crisis represented a major physical and psychological health threat to populations worldwide, making coping and adaptational efforts necessary (Aravena et al. 2020). Recent research findings suggest that the COVID-19 pandemic caused various stress-related symptoms and anxiety for many people around the world (e.g., Casagrande et al. 2020; González-Sanguino et al. 2020). From the perspective of stress theory, it is important to note that the crisis came without warning and did not allow time to anticipate or prepare. Established stress research has shown that anticipation and prediction may increase feelings of control over stressors and thus reduce overall stress (Lazarus 1993). However, more recent work has also suggested that stress experiences in day-to-day life may increase "when you see it coming" (Neubauer et al. 2018). That said, the COVID-19 crisis may at least be partially similar to a natural disaster and may have similar consequences. This is relevant because there are findings suggesting that older adults exhibit higher resilience during natural disasters and have more positive outcomes than other age groups (Eshel et al. 2016; Rafiey et al. 2016; but see Parker et al. 2016 for opposing evidence). A recent study also found that older adults showed high levels of resilience and perceived themselves to be coping well during the initial phase of the COVID-19 pandemic (Fuller and HusethZosel 2021). In addition, previous research on the so-called 
Table 1 Descriptive statistics (at t1)

\begin{tabular}{|c|c|c|c|c|c|c|c|c|c|}
\hline & \multicolumn{3}{|l|}{ All } & \multicolumn{3}{|c|}{ Age 40-64 } & \multicolumn{3}{|c|}{ Age $65-79$} \\
\hline & Mean & SD & $N$ & Mean & SD & $N$ & Mean & SD & $N$ \\
\hline Age $65-79$ & 0.13 & 0.34 & 3098 & & & & & & \\
\hline Women & 0.73 & 0.45 & 3090 & 0.75 & 0.43 & 2677 & 0.59 & 0.49 & 413 \\
\hline Partnered & 0.73 & 0.44 & 3070 & 0.74 & 0.44 & 2664 & 0.68 & 0.47 & 406 \\
\hline University degree & 0.77 & 0.42 & 3058 & 0.77 & 0.42 & 2654 & 0.75 & 0.43 & 404 \\
\hline Working & 0.85 & 0.36 & 3016 & 0.93 & 0.25 & 2628 & 0.26 & 0.44 & 388 \\
\hline Self-rated pre-pandemic physical health ${ }^{\mathrm{a}}$ & 2.10 & 0.82 & 3091 & 2.10 & 0.81 & 2679 & 2.09 & 0.84 & 412 \\
\hline Town size $>50,000$ inhabitants & 0.67 & 0.47 & 3082 & 0.68 & 0.47 & 2671 & 0.61 & 0.49 & 411 \\
\hline$N$ & 3098 & & & 2685 & & & 413 & & \\
\hline
\end{tabular}

${ }^{\mathrm{a}}$ Five-point scale, higher values indicate poorer health

well-being paradox supports the notion that general life satisfaction is high in older adults and relatively robust against stress experiences (Diehl et al. 2020; Kunzmann et al. 2000).

\section{Hypotheses}

As suggested by the conceptual models applied to the COVID-19 crisis as outlined above, we examined two hypotheses relating to satisfaction ratings and explore possible recovery effects over the course of the pandemic. First, applying socio-emotional selectivity theory and the positivity effect to the COVID-19 crisis, we expected the crisis to have caused stronger decreases in satisfaction with social contacts and family life than in satisfaction with life in general among both middle-aged and older adults. Given the positivity effect in old age, we also expected the decreases in satisfaction with social contacts to be more pronounced among middle-aged adults than among older adults. Second, we expected a decrease in general life satisfaction as a result of the stress caused by the COVID-19 crisis that was of similar magnitude among both middle-aged and older adults. We also explored whether recovery effects occurred during the lockdown that followed the pandemic's outbreak in Germany as suggested by the psycho-adaptational literature on critical life events (Luhmann et al. 2012; Schilling and Wahl 2006).

\section{Research design and methods}

\section{Sample and design}

In our analyses, we drew on three waves of survey data gathered in an online survey to capture individuals' everyday experiences during the COVID-19 lockdown in Germany. The survey started one week after Germany went into a nationwide lockdown, which entailed the closure of schools, shops, restaurants, and businesses and the prohibition of public gatherings. Participants learned about the study through e-mail lists, newspaper announcements, and instant messaging services. Participants who agreed to be surveyed again were invited to participate in a follow-up survey 3.5-4 weeks after they completed the first questionnaire and again ten weeks after the first interview. The first wave of data collection ran between March 23, 2020, and May 11, 2020. The second wave of data collection (April 20-June 14, 2020) coincided with the tentative lifting of the lockdown, including the limited reopening of schools and shops. The third wave (June 3-August 2, 2020) coincided with further steps toward reopening, including the decision to restart regular schooling after the summer holidays and the government's presentation of its economic stimulus package.

The entire sample amounted to 14,754 individuals aged 18 years and older in survey wave 1 (W1), 7573 in wave 2 (W2), and 6397 in wave 3 (W3). In our analytical sample, we included those 3098 participants aged 40-79 years who participated in all three waves (see Hipp and Bünning 2020 for a similar approach). Data from participants aged 80 years and older were excluded from our analyses due to the relatively low sample size and the selectivity of "onliners" in this age category (see, for example, Schlomann et al. 2020). Due to our theoretical interest, our analyses distinguished between middle-aged individuals (40-64 years) and older individuals (65-79 years). More than $13 \%$ of the respondents in the analytical sample $(N=413)$ were aged between 65 and 79 years. Besides the differences in chronological age between the two groups, these two age groups differ substantially with regard to their labor force participation and their childcare and other care activities.

As can be seen in Table 1, the majority of participants were female $(73 \%)$, partnered $(73 \%)$, and highly educated (77\% of all participants had a university degree). In total, $85 \%$ of all participants were employed (age group 40-64: 93\%, age group 65-79: 26\%). Self-rated pre-pandemic physical health was 2.10 on a five-point scale in the whole sample.

The sociodemographic characteristics of individuals who participated in all three survey waves were very similar to those of the full W1 sample (see Table 1-Supplement). 
To assess respondents' situations before the COVID-19 crisis began, we included several retrospective questions (t0). To minimize inaccurate answering behaviors due to the high cognitive load of retrospective questions (Yan and Tourangeau 2007) and social desirability biases (Jaspers et al. 2009), we ensured that questions about the respondents' pasts were short, easy to understand, and referred to a specific anchor point (the pre-pandemic period) that was only a short time (2-6 weeks) before data collection. All of these factors have been shown to increase recall accuracy, even for subjective assessments such as ratings of health status and subjective well-being (Barsky 2002), and recall accuracy was found to be independent of respondents' age or educational background (Hipp et al. 2020).

\section{Measures}

\section{Psychosocial adaptation}

Respondents were asked about their satisfaction (measured on a seven-point Likert scale) with family life, the quality of social contacts (including contact by telephone, e-mail, and other media), and satisfaction with life in general. ${ }^{1}$ All three satisfaction ratings were single-item questions. Single-item measures are a commonly used and cost-effective method in survey research, and single-item measures of life satisfaction have been found to be reasonably valid (see Richter et al. 2017, for an overview).

\section{Covariates}

The following covariates were included in the multivariate analyses: gender (female/male), presence of partner in the household (dummy), level of education (dummy variable indicating university degree), whether the person was working (dummy), self-reported physical health prior to the pandemic (one item, five-point Likert scale, adapted from the German Socio-Economic Panel), and the size of the town or city where respondents reside (greater/fewer than 50,000 residents). The presence of a partner and employment status was assessed in each wave; the remaining variables were assessed at $\mathrm{t} 1$.

\section{Data analysis}

The survey data were analyzed using OLS regressions with clustered, robust standard errors using four points

\footnotetext{
1 Additionally, we collected data on respondents' satisfaction with work (among the employed), their relationship and their division of household labor (among partnered persons), as well as satisfaction with neighborhood solidarity. In this paper, however, our focus is on the social domain and on satisfaction with life in general.
}

of measurement ( $\mathrm{t} 0$ [retrospective assessment] to $\mathrm{t} 3$ ). We conducted separate analyses for each life domain. To test whether the coefficients significantly differed by age group and time point, we included interaction effects for age and time point. To compare coefficients across life domains, we used seemingly unrelated regressions and $\chi 2$-tests. To assess the robustness of our results, in particular the theoretically derived age group comparison, we conducted the following robustness checks: First, we used age as a continuous variable (age and age squared) instead of distinguishing between the two age groups. Second, we replicated the analyses based on the full sample of 6510 respondents who participated in wave 1 and using full information maximum likelihood (Enders 2001).

\section{Results}

We start by presenting mean levels of all satisfaction ratings across the four time points for the two age groups separately (Fig. 1). Satisfaction ratings decreased in both age groups for general life satisfaction and for satisfaction with family life and quality of social contacts at the beginning of the pandemic and recovered to some extent in the last observation period.

\section{Psychosocial adaptation across time}

Findings from the OLS regressions are summarized in Table 2. Respondents from both age groups reported significantly higher levels of satisfaction with life in general, family life, and the quality of social contacts before the beginning of the pandemic ( $\mathrm{t} 0$ ) than during the first weeks of lockdown (reference category).

Comparing the size of the coefficients between age groups, we found decreases in general life satisfaction and satisfaction with the quality of social contact to be more pronounced among middle-aged adults than older adults. In fact, coefficients were almost twice as high in the middleaged group, and the differences in the size of the coefficients were statistically significant (see Table 2-Supplement). Satisfaction with family life, by contrast, decreased to a similar extent in both age groups.

Comparing the changes in satisfaction across different areas of life, we found that decreases in satisfaction with contact quality were most pronounced in both age groups. Among middle-aged respondents, decreases in general life satisfaction came second, followed by decreases in satisfaction with family life, whereas older respondents' satisfaction with both areas decreased to a similar extent (see Table 4-Supplement).

In addition, there was little evidence of recovery at $\mathrm{t} 2$ (in the middle of the lockdown period) compared to t1. In 


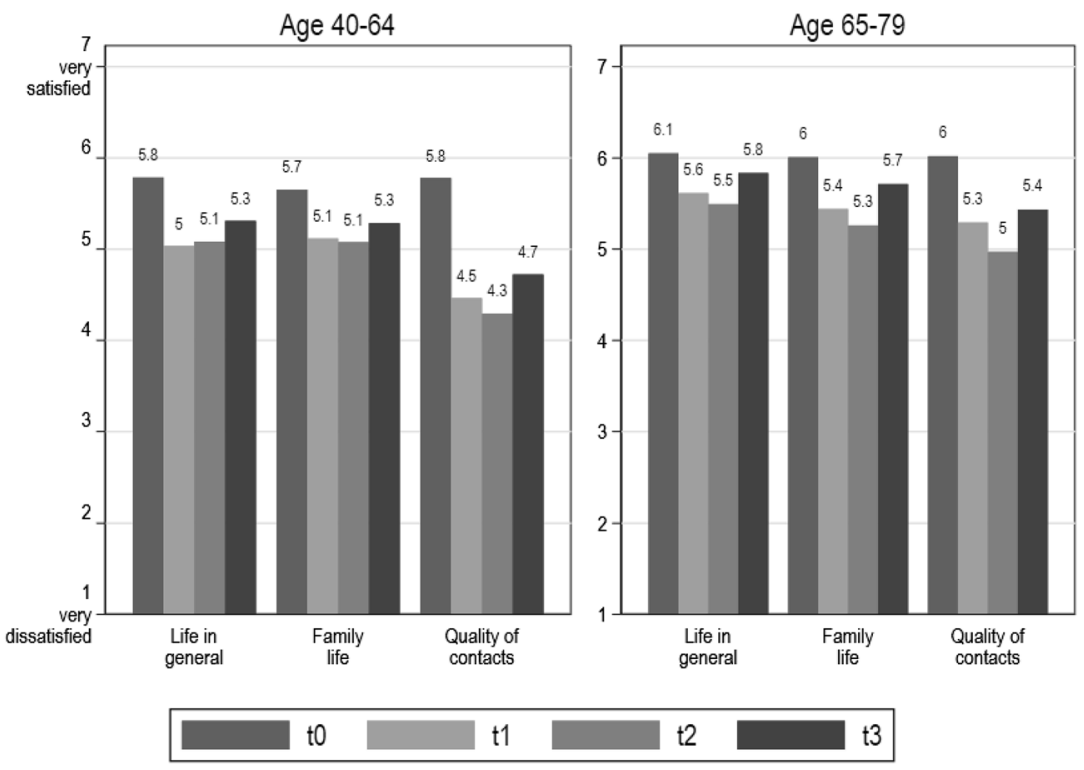

Note: Mean values for satisfaction ratings across time; $\mathrm{t} 0$ : retrospective assessment of pre-pandemic situation assessed at $\mathrm{t} 1, \mathrm{t} 1$ : assessed March 23 to May 11, 2020, t2: assessed 3.5 to 4 weeks after t1 (April 20 to June 14, 2020), t3: assessed 10 weeks after t1 (June 3 to August 20, 2020).

Fig. 1 Sample means of satisfaction ratings by age group and measurement occasion

contrast, older respondents' satisfaction with all three life domains tended to deteriorate further, as did middle-aged respondents' satisfaction with social contacts. Middle-aged respondents' satisfaction with life in general and family life remained stable. Yet we observed partial recovery toward the end of the lockdown (hence, approximately four months after the start of the lockdown). Although both older and middle-aged respondents reported higher levels of life satisfaction and satisfaction with family and social contacts at $\mathrm{t} 3$ than at $\mathrm{t} 1$, older adults had a stronger recovery in general life satisfaction and satisfaction with social contacts than middle-aged adults when comparing their ratings at $\mathrm{t} 3$ to the pre-pandemic period ( $\mathrm{t} 0$ ). Recovery in satisfaction with family life was similar for both age groups (see Table 3-Supplement). Note, however, that satisfaction ratings in all three dimensions remained considerably below pre-pandemic levels.

\section{Robustness checks}

To assess the robustness of our findings, we replicated the analysis using a continuous measure of age (linear and squared). Figure 2 displays changes in all three life domains across the three waves over time (taking t 1 as the reference category). The younger the respondents were, the greater their decrease in life satisfaction at the onset of the lockdown ( $\mathrm{t} 0$ vs. $\mathrm{t} 1$, almost linear relationship). Between $\mathrm{t} 1$ and $\mathrm{t} 2$, life satisfaction remained unchanged across the entire life span (95\% confidence intervals always include 0 ). Increases in life satisfaction at $\mathrm{t} 3$ (compared to $\mathrm{t} 1$ ) were somewhat more pronounced at both ends of the age distribution than at the middle of the age distribution. While the oldest individuals returned to pre-pandemic levels of life satisfaction at $\mathrm{t} 3$, life satisfaction of respondents aged 67 years and younger remained considerably below pre-pandemic levels.

Decreases in satisfaction in family life between t0 and t1 were similar across the entire age span and continued to decrease at $\mathrm{t} 2$. Decreases at $\mathrm{t} 2$ were most pronounced for the oldest respondents (but note the large confidence intervals). At $\mathrm{t} 3$, satisfaction with family life increased again to similar degrees across the entire life span, but remained below the pre-pandemic level ( $\mathrm{t} 0$ ).

For satisfaction with the quality of social contacts, the younger the respondents, the more pronounced the decrease in satisfaction between $\mathrm{t} 0$ and $\mathrm{t} 1$. The association was not linear, however, and leveled off in higher age groups, i.e., there were no differences between 60 - and 79 -year-olds. At $\mathrm{t} 2$, satisfaction with the quality of social contacts decreased further and did so to a similar degree across the entire age span. At $t 3$, satisfaction with the quality of social contacts increased again across the entire age distribution. These increases were nonlinear and more pronounced at both ends than in the middle of the age distribution. For all ages, however, satisfaction levels at $\mathrm{t} 3$ remained below pre-pandemic levels, with a particularly large gap among the youngest respondents.

In addition, we replicated our original analyses using the full sample of respondents who participated in the survey at 
Table 2 OLS regressions on satisfaction with different domains of life using t1 as reference

\begin{tabular}{|c|c|c|c|c|c|c|}
\hline & \multicolumn{2}{|l|}{ Life } & \multicolumn{2}{|l|}{ Family } & \multicolumn{2}{|l|}{ Contacts } \\
\hline & $40-64$ & $65-79$ & $40-64$ & $65-79$ & $40-64$ & $65-79$ \\
\hline \multirow[t]{2}{*}{ to } & $0.76^{* * *}$ & $0.43^{* * *}$ & $0.54^{* * * *}$ & $0.50^{* * *}$ & $1.34^{* * *}$ & $0.73^{* * *}$ \\
\hline & {$[0.71,0.81]$} & {$[0.33,0.53]$} & {$[0.48,0.60]$} & {$[0.37,0.63]$} & {$[1.26,1.41]$} & {$[0.59,0.88]$} \\
\hline \multirow[t]{2}{*}{$\mathrm{t} 2$} & 0.04 & -0.09 & -0.04 & -0.17 & $-0.18^{* * *}$ & $-0.28^{* *}$ \\
\hline & {$[-0.00,0.09]$} & {$[-0.25,0.06]$} & {$[-0.10,0.02]$} & {$[-0.36,0.01]$} & {$[-0.24,-0.11]$} & {$[-0.45,-0.11]$} \\
\hline \multirow[t]{2}{*}{$\mathrm{t} 3$} & $0.28^{* * *}$ & $0.21^{* *}$ & $0.18^{* * * *}$ & $0.24^{* *}$ & $0.27^{* * *}$ & 0.17 \\
\hline & {$[0.23,0.33]$} & {$[0.06,0.36]$} & {$[0.12,0.24]$} & {$[0.06,0.42]$} & {$[0.20,0.34]$} & {$[-0.00,0.34]$} \\
\hline \multirow[t]{2}{*}{ Women } & $-0.12^{* *}$ & -0.06 & -0.04 & $-0.23^{*}$ & $0.11^{*}$ & 0.06 \\
\hline & {$[-0.20,-0.03]$} & {$[-0.26,0.13]$} & {$[-0.14,0.06]$} & {$[-0.45,-0.01]$} & {$[0.02,0.21]$} & {$[-0.16,0.28]$} \\
\hline \multirow[t]{2}{*}{ Partnered } & $0.21^{* * *}$ & 0.05 & $0.53^{* * *}$ & $0.38^{* *}$ & $-0.27^{* * *}$ & $-0.36^{* *}$ \\
\hline & {$[0.12,0.30]$} & {$[-0.16,0.25]$} & {$[0.42,0.63]$} & {$[0.13,0.64]$} & {$[-0.37,-0.18]$} & {$[-0.60,-0.11]$} \\
\hline \multirow[t]{2}{*}{ University degree } & 0.03 & -0.06 & -0.01 & -0.11 & $-0.11^{*}$ & -0.09 \\
\hline & {$[-0.06,0.13]$} & {$[-0.28,0.16]$} & {$[-0.12,0.09]$} & {$[-0.36,0.14]$} & {$[-0.21,-0.01]$} & {$[-0.33,0.15]$} \\
\hline \multirow[t]{2}{*}{ Working } & $0.18^{*}$ & -0.15 & 0.06 & -0.13 & 0.11 & 0.00 \\
\hline & {$[0.01,0.35]$} & {$[-0.34,0.05]$} & {$[-0.12,0.24]$} & {$[-0.36,0.11]$} & {$[-0.06,0.29]$} & {$[-0.21,0.21]$} \\
\hline \multirow[t]{2}{*}{ Health } & $-0.39^{* * *}$ & $-0.28^{* * *}$ & $-0.35^{* * *}$ & $-0.24^{* * *}$ & $-0.18^{* * *}$ & $-0.15^{*}$ \\
\hline & {$[-0.44,-0.34]$} & {$[-0.39,-0.16]$} & {$[-0.41,-0.29]$} & {$[-0.38,-0.11]$} & {$[-0.24,-0.13]$} & {$[-0.28,-0.03]$} \\
\hline \multirow[t]{2}{*}{ Town size $>50,000$} & $-0.11^{*}$ & -0.07 & $-0.10^{*}$ & 0.02 & $-0.09^{*}$ & 0.01 \\
\hline & {$[-0.19,-0.02]$} & {$[-0.27,0.12]$} & {$[-0.19,-0.00]$} & {$[-0.21,0.25]$} & {$[-0.19,-0.00]$} & {$[-0.22,0.23]$} \\
\hline \multirow[t]{2}{*}{ Constant } & $5.78^{* * *}$ & $6.43^{* * *}$ & $5.61^{* * * *}$ & $5.98^{* * *}$ & $5.09^{* * * *}$ & $5.86^{* * *}$ \\
\hline & {$[5.50,6.07]$} & {$[5.90,6.96]$} & {$[5.31,5.91]$} & {$[5.35,6.61]$} & {$[4.80,5.38]$} & {$[5.23,6.50]$} \\
\hline$N$ (persons) & 2637 & 402 & 2636 & 400 & 2637 & 402 \\
\hline$N$ (observations) & 10,188 & 1509 & 10,044 & 1486 & 10,190 & 1514 \\
\hline$R^{2}$ & 0.12 & 0.06 & 0.09 & 0.08 & 0.15 & 0.09 \\
\hline
\end{tabular}

Coefficients stem from OLS regressions with clustered, robust standard errors; confidence intervals provided in parentheses

$* p<0.05 ; * * p<0.01 ; * * * p<0.001$

least once and full information maximum likelihood estimation (FIML, see Table 5-Supplement). The results of these analyses are similar to those presented in Table 2, with the exception of life satisfaction among the younger age group, which increased somewhat at $\mathrm{t} 2$ compared to $\mathrm{t} 1$ in the FIML (but not in the OLS) models.

\section{Discussion}

This study explored differences in satisfaction with social life and life in general between middle-aged individuals (40-64 years) and older individuals (65-79 years) during the COVID-19 pandemic in Germany. Based on an online survey with more than 3000 respondents, we found that psychological adaptation to the COVID-19 pandemic differed to some extent between middle-aged and older individuals and that the reactions to the lockdown were contingent on the satisfaction domain as well as age.

In line with our first hypothesis, we observed the most pronounced decreases in satisfaction with the quality of social contacts and found that the decrease was more pronounced among middle-aged than older adults. In addition, the recovery in satisfaction ratings toward the end of the lockdown was stronger among older adults. More precisely, we observed a larger recovery in older adults' satisfaction with social contacts compared to middle-aged individuals, with a particularly low level of satisfaction among the youngest persons in our sample. Still, the satisfaction levels remained below the pre-pandemic levels across the age range.

These findings suggest that the positivity effect as described by socio-emotional selectivity theory (Carstensen 2006; English and Carstensen 2016) may have protected older adults from experiencing or suffering from social isolation to some extent. Older adults tend to process negative information (such as the pandemic) less intensively than younger individuals due to their reduced future time perspective and may have a stronger tendency to emphasize positive side effects of the COVID-19 pandemic and to generally take a more positive view. In addition, older adults' higher psychosocial resilience to challenges arising from COVID-19 may result from their accumulated life experiences (Staudinger 1999) and higher flexibility in downsizing 

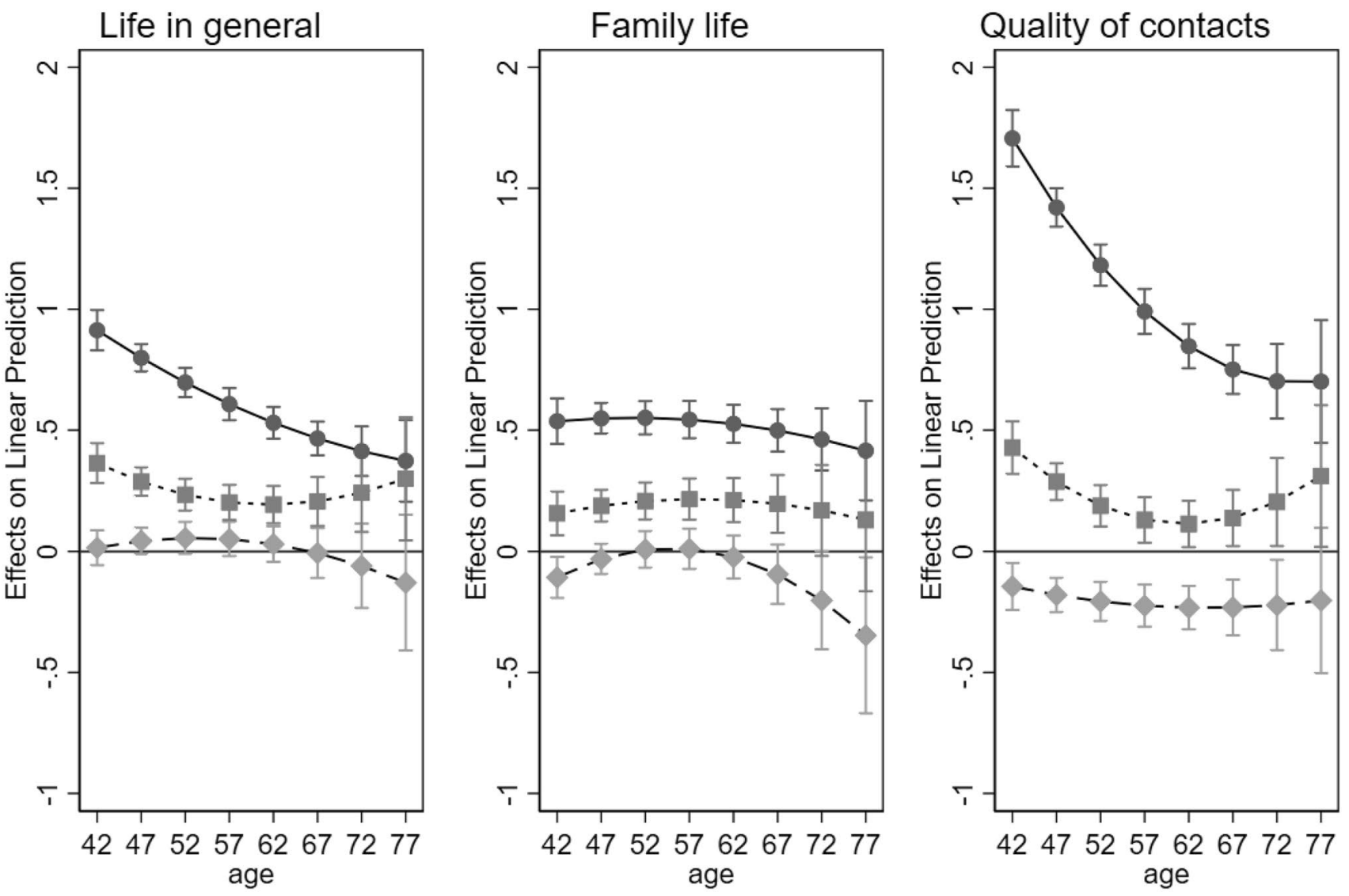

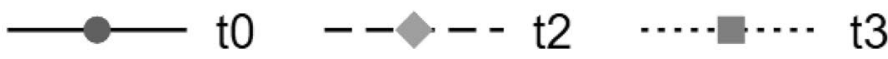

Fig. 2 OLS regressions on satisfaction with different domains of life using age as continuous variable. Note Predicted changes in satisfaction ratings compared to $t 1$ across age at three time points; t0: retrospective assessment of pre-pandemic situation assessed at $\mathrm{t} 1, \mathrm{t} 1$ : assessed March 23-May 11, 2020, t2: assessed 3.5-4 weeks after t1

social aspirations (Brandtstädter 2006); both processes may lead to higher satisfaction even in disadvantageous social situations. This may also indicate higher psychosocial resilience of older adults during the COVID-19 pandemic, as has been shown previously for natural disasters (Eshel et al. 2016; Rafiey et al. 2016) and which is consistent with recent findings on the COVID-19 pandemic. In a US-based study, Carney et al. (2021) reported a significant interaction effect between age and perceived COVID-19 disruption on stress and negative affect, indicating a less negative impact on well-being in increased age (see also Fuller and HusethZosel 2021). In their analyses of German Socio-Economic Panel data, Entringer and Kröger (2020) found that loneliness increased among both younger and older age groups but that the increase was less pronounced among older adults. Similar trends in the results were found in studies by Luchetti et al. (2020) in the USA and Bu et al. (2020a;
(April 20-June 14, 2020), t3: assessed 10 weeks after t1 (June $3-$ August 20, 2020). Age is measured by a linear and squared term. The models additionally include gender, partnership status, employment status, health, and size of town where respondents reside

2020b) in the UK, but the comparison group in this work was younger (18-29 years) than in our study (40-64 years).

In accordance with our second hypothesis, we also found decreases in general life satisfaction among both middleaged (40-64 years) and older participants (65-79 years) compared to before the crisis ( $\mathrm{t} 1-\mathrm{t} 0$ ). Again, the decrease was more pronounced among middle-aged adults. Only the oldest participants in our analytical sample returned to prepandemic levels of satisfaction with life in general. Besides the aforementioned explanations referring to positivity and resilience-like factors (Eshel et al. 2016; Rafiey et al. 2016; Fuller and Huseth-Zosel 2021), the established well-being paradox in old age, also labeled the "stability despite loss" paradigm (Kunzmann et al. 2000), may help in explaining the age-differential impact of the COVID-19 crisis on general life satisfaction. 
An important feature of our research design was the inclusion of a second and third measurement point during the lockdown period in Germany. Interestingly, we observed no recovery in any satisfaction domain between $\mathrm{t} 1$ (the start of the first lockdown in Germany) and $\mathrm{t} 2$ (the phase during which lockdown measures began to be lifted). Instead, satisfaction with the quality of social contacts deteriorated even further across both age groups in the early months of the lockdown. We observed some recovery for both age groups and across life domains only at $\mathrm{t} 3$, hence about 4-5 months after the baseline, when life in Germany had returned to close to "normal" but satisfaction ratings remained largely below pre-pandemic levels.

While our survey provided us with a large number of participants throughout Germany and allowed us to track developments over time starting immediately after the first lockdown measures went into effect in March 2020, there are also a few potential biases of online surveys with voluntary participation that need to be discussed. First, although we included a broad range of covariates in our analyses to address the fact that our data came from a nonprobability online survey, and the fact that different sociodemographic groups varied in their likelihood to participate, our estimates may nonetheless be biased with regard to education, gender, and in particular, the usage of the technology necessary for an online study.

Second, intervening variables and unobserved characteristics such as attitudes and compensation strategies could not be considered as covariates because they were not included in the survey study. However, other empirical findings suggest that individuals were affected in different ways by psychological distress and anxiety caused by the COVID-19 pandemic. For example, spiritual well-being was a protective factor for depression and anxiety caused by the COVID-19 pandemic, whereas higher loneliness was associated with a more negative psychological impact (GonzálezSanguino et al. 2020). These possible effects should be considered in more detail in future studies applying longitudinal approaches.

Third, our analyses only included relatively healthy community-dwelling older adults, who experienced much less dramatic social consequences during the lockdown than older people in long-term care facilities. Thus, we have not addressed the very high-risk constellation of factors that affected people living in nursing homes (European Centre for Disease Prevention and Control 2020), and we cannot make any statements about older people who receive a high level of care in their private homes. Moreover, we did not include individuals aged 80 years and older in order to avoid further selection biases. It would, however, be very important to also consider adults in nursing homes and people of very old age in future COVID-19 studies on psychosocial adaptation due their very different physical and mental abilities and thus their reduced resource status (Baltes and Smith 2003).

Fourth, our findings with regard to the respondents' retrospective assessments of their pre-pandemic well-being ( $\mathrm{t} 0$ ) should also be interpreted cautiously. Despite the fact that asking retrospective questions has been increasingly used to provide a more comprehensive view of earlier phases of the life course in surveys on middle-aged and older adults (Börsch-Supan and Schröder 2011), debate continues on the measurement quality of retrospective assessment due to its proneness to inaccuracies and answering biases (Jürges 2007). In the case of this study, however, our results are most likely to be conservative, as research on retrospective questions during COVID-19 found that respondents tend to remember their past as more similar to their present (and not more idealized) when the experience or feeling of interest has changed between the time of the interview and the time point of interest (Hipp et al. 2020).

In conclusion, although ageism in the form of labeling older adults as "the risk group" occurred during the pandemic and might have caused psychological harm (Ayalon et al. 2021; Ehni and Wahl 2020), the current study found that both middle-aged and older individuals experienced decreases in a number of satisfaction ratings. However, in accordance with other large longitudinal studies, the decreases were more pronounced in middle-aged adults than in older adults. Furthermore, older adults showed a greater recovery in the general domain and in satisfaction with quality of social contacts compared to middle-aged adults.

The policy implications that can be derived from these findings can be summarized as follows: First, older adults showed a relatively high level of psychosocial resilience and recovery during the COVID-19 pandemic, which means that they should not be patronized and labeled as "risk groups"not even with the best of intentions. It is important not only to protect older persons but to extend concerns about their well-being to society as a whole. Public decision makers and the media should therefore take more action to consider the heterogeneity in the group of the "silver agers" and "baby boomers" and should stress intergenerational solidarity.

Second, the large decrease in satisfaction with social contacts may indicate that older as well as middle-aged individuals may run into the risk of loneliness, which may eventually negatively affect their physical and mental health (see also Tyrrell and Williams 2020). The provision of comprehensive information about measures (e.g., vaccinations) may therefore help to define a future time perspective and buffer negative effects. Still, the long-term effects have not yet been studied, and future research will be needed to address the issues of psychosocial adaptation and possible negative effects of the pandemic over the life course. 
Supplementary Information The online version contains supplementary material available at https://doi.org/10.1007/s10433-021-00655-1.

Author contributions All authors contributed to the study conception and design and wrote the manuscript. Anna Schlomann and Mareike Bünning contributed equally to the paper. Material preparation, data collection, and analyses were performed by Mareike Bünning and Lena Hipp. All authors read and approved the final manuscript.

Funding Open Access funding enabled and organized by Projekt DEAL. This work was supported by Bundesministerium für Bildung und Forschung (Grant Number 01UG1806).

Data availability All data are available at https://doi.org/10.7802/2042. Replication files for the analyses are available in the Supplementary Material for reviewers.

\section{Declarations}

Conflict of interest The authors have no conflicts of interest to declare.

Ethical standard The study was approved by the Ethics Commission at the WZB Berlin Social Science Center.

Informed consent Informed consent was obtained from all participants included in the study.

Open Access This article is licensed under a Creative Commons Attribution 4.0 International License, which permits use, sharing, adaptation, distribution and reproduction in any medium or format, as long as you give appropriate credit to the original author(s) and the source, provide a link to the Creative Commons licence, and indicate if changes were made. The images or other third party material in this article are included in the article's Creative Commons licence, unless indicated otherwise in a credit line to the material. If material is not included in the article's Creative Commons licence and your intended use is not permitted by statutory regulation or exceeds the permitted use, you will need to obtain permission directly from the copyright holder. To view a copy of this licence, visit http://creativecommons.org/licenses/by/4.0/.

\section{References}

Aravena JM, Aceituno C, Nyhan K, Shi S, Vermund S, Levy BR (2020) Drawing on wisdom to cope with adversity:' a systematic review protocol of older adults' mental and psychosocial health during acute respiratory disease propagated-type epidemics and pandemics (COVID-19, SARS-CoV, MERS, and Influenza). Preprint, medRxiv. https://doi.org/10.1101/2020.06.04.20122812

Ayalon L, Chasteen A, Diehl M, Levy B, Neupert SD, Rothermund K, Tesch-Römer C, Wahl H-W (2021) Aging in times of the COVID19 pandemic: avoiding ageism and fostering intergenerational solidarity. J Gerontol B Psychol Sci Soc Sci 76:e49-e52. https:// doi.org/10.1093/geronb/gbaa051

Baltes PB, Smith J (2003) New frontiers in the future of aging: from successful aging of the young old to the dilemmas of the fourth age. Gerontology 49:123-135. https://doi.org/10.1159/000067946

Barsky AJ (2002) Forgetting, fabricating, and telescoping. Arch Intern Med 162(9):981-984. https://doi.org/10.1001/archinte.162.9.981
Börsch-Supan M, Schröder M (2011) Retrospective data collection in the survey of health, ageing and retirement in Europe. SHARELIFE Methodol 5-10

Brandtstädter J (2006) Action perspectives on human development. In: Damon W, Lerner RM (eds) Handbook of child psychology: vol 1. Theoretical models of human development, 6th edn. Wiley, New York, pp 516-568

Bu F, Steptoe A, Fancourt D (2020a) Loneliness during lockdown: trajectories and predictors during the COVID-19 pandemic in 35,712 adults in the UK. Preprint, medRxiv. https://doi.org/10. $1101 / 2020.05 .29 .20116657$

Bu F, Steptoe A, Fancourt D (2020b) Who is lonely in lockdown? Cross-cohort analyses of predictors of loneliness before and during the COVID-19 pandemic. Preprint, medRxiv. https:// doi.org/10.1101/2020.05.14.20101360

Carney AK, Graf AS, Hudson G, Wilson E (2021) Age moderates perceived COVID-19 disruption on well-being. Gerontologist 61:30-35. https://doi.org/10.1093/geront/gnaa106

Carstensen LL (2006) The influence of a sense of time on human development. Science 30:1913-1915. https://doi.org/10.1126/ science. 1127488

Casagrande M, Favieri F, Tambelli R, Forte G (2020) The enemy who sealed the world: Effects quarantine due to the COVID-19 on sleep quality, anxiety, and psychological distress in the Italian population. Sleep Med 75:12-20. https://doi.org/10.1016/j. sleep.2020.05.011

Cesari M, Proietti M (2020) Geriatric medicine in Italy in the time of COVID-19. J Nutr Health Aging 24:1-2. https://doi.org/10. 1007/s12603-020-1354-z

Diehl M, Brothers AF, Wahl H-W (2020) Self-perceptions and awareness of aging: past, present, and future. In: Schaie KW, Willis SL (eds) Handbook of the psychology of aging, 8th edn. Elsevier, New York

Ehni HJ, Wahl H-W (2020) Six propositions against ageism in the COVID-19 pandemic. J Aging Soc Policy 4-5:515-525. https:// doi.org/10.1080/08959420.2020.1770032

Enders CK (2001) The performance of the full information maximum likelihood estimator in multiple regression models with missing data. Educ Psychol Meas 61(5):713-740. https://doi. org/10.1177/0013164401615001

English T, Carstensen LL (2016) Socioemotional selectivity theory. In: Pachana N (ed) Encyclopedia of geropsychology. Springer, New York. https://doi.org/10.1007/978-981-287-080-3_110-1

Entringer TM, Kröger H (2020) Einsam, aber resilient-Die Menschen haben den Lockdown besser verkraftet als vermutet [Lonely but resilient-People have coped with the lockdown better than expected] (Paper No. 46). DIW Berlin, German Institute for Economic Research. http://hdl.handle.net/10419/ 222876. Accessed 24 Sept 2020

Eshel Y, Kimhi S, Lahad M, Leykin D (2016) Individual, community, and national resiliencies and age: are older people less resilient than younger individuals? Am J Geriatr Psychiatry 24(8):644-647. https://doi.org/10.1016/j.jagp.2016.03.002

European Centre for Disease Prevention and Control (2020) Surveillance of COVID-19 at long-term care facilities in the EU/ EEA. Technical Report. https://www.ecdc.europa.eu/sites/defau 1t/files/documents/COVID-19-long-term-care-facilities-surve illance-guidance.pdf. Accessed 24 June 2020

Fuller HR, Huseth-Zosel A (2021) Lessons in resilience: initial coping among older adults during the COVID-19 pandemic. Gerontologist 61:114-125. https://doi.org/10.1093/geront/gnaa170

González-Sanguino C, Ausín B, Ángel Castellanos M, Saiz J, López-Gómez A, Ugidos C, Muñoz M (2020) Mental health 
consequences during the initial stage of the 2020 Coronavirus pandemic (COVID-19) in Spain. Brain Behav Immun 87:172176. https://doi.org/10.1016/j.bbi.2020.05.040

Heid AR, Cartwright F, Wilson-Genderson M, Pruchno R (2021) Challenges experienced by older people during the initial months of the COVID-19 pandemic. Gerontologist 61:48-58. https://doi.org/10.1093/geront/gnaa138

Hipp L, Bünning M (2020) Parenthood as a driver of increased gender inequality during COVID-19? Exploratory evidence from Germany. Eur Soc. https://doi.org/10.1080/14616696.2020.1833229

Hipp L, Bünning M, Munnes S, Sauermann A (2020) Problems and pitfalls of retrospective survey questions in COVID-19 studies. Surv Res Methods 14:109-114. https://doi.org/10.18148/srm/ 2020.v14i2.7741

Jaspers E, Lubbers M, Graaf NDD (2009) Measuring once twice: an evaluation of recalling attitudes in survey research. Eur Sociol Rev 25(3):287-301. https://doi.org/10.1093/esr/jcn048

Jiminez-Sotomayor MR, Gomez-Moreno C, Soto-Perez-de-Celis E (2020) Coronavirus, ageism, and Twitter: an evaluation of Tweets about older adults and COVID-19. J Am Geriatr Soc 68(8):16611665. https://doi.org/10.1111/jgs. 16508

Jürges H (2007) Unemployment, life satisfaction, and retrospective error. J R Stat Soc Ser A Stat Soc 170(1):43-61

Kunzmann U, Little TD, Smith J (2000) Is age-related stability of subjective well-being a paradox? Cross-sectional and longitudinal evidence from the Berlin Aging Study. Psychol Aging 15:511526. https://doi.org/10.1037/0882-7974.15.3.511

Lazarus RS (1993) Coping theory and research: past, present, and future. Psychosom Med 55:234-247. https://doi.org/10.1097/ 00006842-199305000-00002

Luchetti M, Lee JH, Aschwanden D, Sesker A, Strickhouser JE, Terracciano A, Sutin AR (2020) The trajectory of loneliness in response to COVID-19. Am Psychol. https://doi.org/10.1037/amp0000690

Luhmann M, Hofmann W, Eid M, Lucas RE (2012) Subjective wellbeing and adaptation to life events: a meta-analysis. J Pers Soc Psychol 102(3):592-615. https://doi.org/10.1037/a0025948

Martin P (2020) The effect of a virus on adult development. J Adult Dev 27:81-82. https://doi.org/10.1007/s10804-020-09353-1

Neubauer AB, Smyth JM, Sliwinski MJ (2018) When you see it coming: stressor anticipation modulates stress effects on negative affect. Emotion 18(3):342-354. https://doi.org/10.1037/emo00 00381

Parker G, Lie D, Siskind DJ et al (2016) Mental health implications for older adults after natural disasters-a systematic review and meta-analysis. Int Psychogeriatr 28(1):11-20. https://doi.org/10. $1017 /$ S1041610215001210
Rafiey H, Momtaz YA, Alipour F et al (2016) Are older people more vulnerable to long-term impacts of disasters? Clin Interv Aging 11:1791-1795. https://doi.org/10.2147/CIA.S122122

Richter D, Rohrer J, Metzing M, Nestler W, Weinhardt M, Schupp J (2017) SOEP Scales Manual (updated for SOEP-Core v32.1). SOEP Survey Papers 423: Series C. Berlin: DIW/SOEP. https:// www.diw.de/documents/publikationen/73/diw_01.c.571151.de/ diw_ssp0423.pdf

Sands LP, Albert SM, Suitor JJ (2020) Understanding and addressing older adults' needs during COVID-19. Innov Aging. https://doi. org/10.1093/geroni/igaa019

Scheibe S, Carstensen LL (2010) Emotional aging: recent findings and future trends. J Gerontol B Psychol Sci Soc Sci 65:135-144. https://doi.org/10.1093/geronb/gbp132

Schilling O, Wahl H-W (2006) Modeling late life adaptation in affective well-being under a severe chronic health condition: the case of age-related macular degeneration. Psychol Aging 21:703-714. https://doi.org/10.1037/0882-7974.21.4.703

Schlomann A, Seifert A, Zank S, Woopen C, Rietz C (2020) Use of ICT devices among the oldest-old: loneliness, anomie, and autonomy. Innov Aging. https://doi.org/10.1093/geroni/igz050

Staudinger UM (1999) Older and wiser? Integrating results from a psychological approach to the study of wisdom. Int J Behav Dev 23:641-664. https://doi.org/10.1080/016502599383739

Tyrrell CJ, Williams KN (2020) The paradox of social distancing: implications for older adults in the context of COVID-19. Psychol Trauma 12(S1):S214-S216. https://doi.org/10.1037/tra0000845

Wolf-Ostermann K, Rothgang H (2020) Zur Situation der Langzeitpflege in Deutschland während der Corona-Pandemie [Situation of long-term care in Germany during the Corona pandemic]. Report published online. https://www.uni-bremen.de/fileadmin/ user_upload/fachbereiche/fb11/Aktuelles/Corona/Ergebnisbe richt_Coronabefragung_Uni-Bremen_24062020.pdf. Accessed 24 Sept 2020

World Health Organization (WHO) (2020). WHO Director-General's opening remarks at the media briefing on COVID-19, March 11, 2020. https://www.who.int/dg/speeches/detail/who-director-gener al-s-opening-remarks-at-the-media-briefing-on-covid-19---11march-2020. Accessed 20 July 2020

Yan T, Tourangeau R (2007) Fast times and easy questions: the effects of age, experience and question complexity on web survey response times. Appl Cogn Psychol 22(1):51-68. https://doi.org/ 10.1002/acp. 1331

Publisher's Note Springer Nature remains neutral with regard to jurisdictional claims in published maps and institutional affiliations. 